\title{
Towards Open Science: The vision of the European Commission
}

\author{
Celina Ramjoué \\ Head of Sector Open Access to Scientific Publications and Data, Digital Science Unit, \\ DG Communications Networks, Content and Technology, European Commission
}

\section{A new Commission and a new initiative: The Digital Single Market and Open Science}

The Digital Single Market is a priority initiative of the new European Commission led by Jean-Claude Juncker. The Digital Single Market is an area in which businesses and individuals can access and exercise online activities under conditions of fair competition, with a high degree of consumer and data protection, irrespective of their nationality or place of residence. ${ }^{1}$

Three European Commissioners are involved with research and innovation issues within the Digital Single Market: Andrus Ansip (Estonia) is Vice President for the Digital Single Market; Günther Oettinger (Germany) is the Commissioner for Digital Economy and Society; and Carlos Moedas (Portugal) is the Commissioner for Research, Science and Innovation. Given the relatively recent emergence of digital markets, high levels of research and innovation characterize the market, with open science an increasingly crucial ingredient.

Commissioner Oettinger, on the occasion of the 10th anniversary of Academic Publishing in Europe, transmitted the following greeting to APE participants: "Ladies and gentlemen, you are meeting in Berlin to discuss the future for scholarly communication and publishing, as you have for the past 10 years. That is impressive. I congratulate you. Scientific publishing is a European success story. In the industry, the EU accounts for about $40 \%$ of employment and one third of revenue. You address issues like open access, open research data, peer review, quality assurance and copyright. From the perspective of the European Commission, the issues you address are connected with a new broad policy initiative, the Digital Single Market - a key priority to be adopted in 2015 . One of its cornerstones is a robust research and innovation policy. In a digital environment, one key ingredient for that is open science. Open Science is the transformation, opening up and democratisation of science research and innovation through information and communication technologies. Open science includes open access, support of e-infrastructures, citizen science, and alternative metrics. It leads to more robust and efficient science, improved transparency, and increased citizen participation. It facilitates innovation through the free circulation of knowledge. A central role of academic publishers has always been to enable knowledge circulation. Digital technologies have made this much easier. It is now time to capitalize on this potential. I rely on academic

\footnotetext{
${ }^{1}$ http://ec.europa.eu/priorities/digital-single-market/.
} 
publishers to contribute to the Digital Single Market by supporting and implementing the open science paradigm."

For the European Commission, open science provides the context for open access to publications and open research data. I will first describe the state of play in open access, and its prospects. Second, I will outline the new implementation of open data policies. Finally, I will return to open science and look at key challenges ahead.

\section{Open Access to publications}

In Horizon 2020, the Research and Innovation Framework Programme running from 2014 to 2020, open access to publications has become mandatory. Each beneficiary of H2020 funding must ensure open access to peer-reviewed publications resulting from $\mathrm{H} 2020$ projects by:

(1) Depositing a machine-readable copy in a repository (preferably compliant with OpenAIRE). ${ }^{2}$

(2) Ensuring open access on publication (gold or green open access), but if green OA is subject to a publisher embargo, then open access should be guaranteed no later than 6 months after publication for STEM subject areas or 12 months for SSH subject areas.

Horizon 2020 open access policy features two additional elements:

(3) Ask, on a best effort basis, for the simultaneous deposit of the underlying research data relating to the publication so that results may be validated.

(4) Ensure open access to the bibliographic metadata that identify the deposited publication.

Open access publication charges are typically covered by grants. The European Commission is seeking to extend coverage beyond the duration of the grant. We will pilot post-grant funding of articleprocessing charges with a budget of 4 million $€$ for publications emerging from research funded by the 7th Research and Innovation Framework Programme (FP7, running until 2013). Post-grant, the European Commission will fund up to three peer-reviewed publications per project, and up to two years until after the project ended, and including books. An example for clarification: A project funded under FP7 in 2012 or 2013 may still be running for several years, e.g. until 2017, so the post-grant phase is not defined by the duration of a Framework Programme, but by the actual duration of the funded project. [Note: this is now launched: https://www.openaire.eu/goldoa/fp7-post-grant/pilot.]

\section{Open Access to research data}

The European Commission is piloting Open Research Data under Horizon 2020. In the current work programme (2014-2015) several areas have been selected to participate. These are:

- Future and Emerging Technologies (FET).

- Research infrastructures - part e-Infrastructures.

- Leadership in enabling and industrial technologies - Information and Communication Technologies (LEIT-ICT).

- Societal Challenge: Secure, Clean and Efficient Energy - part Smart cities and communities.

\footnotetext{
${ }^{2}$ https://www.openaire.eu.
} 
- Societal Challenge: Climate Action, Environment, Resource Efficiency and Raw materials - except raw materials.

- Societal Challenge: Europe in a changing world - inclusive, innovative and reflective Societies.

- Science with and for Society.

Based on the data management plan that beneficiaries of $\mathrm{H} 2020$ funding must submit, the researchers will be asked to:

(1) Deposit underlying and any other relevant data in a data repository of their choice.

(2) Take appropriate measures to ensure that the data can be accessed, exploited, reproduced, and disseminated free of charge.

(3) Provide information on the tools and instruments required for validating research results, which may include access to them.

While the pilot is running, researchers are not required to make all datasets available. Also, researchers in other areas than those listed above may join voluntarily. Data on the initial take-up are as follows: On the basis of 3054 funded Horizon 2020 proposals, there was an opt-out rate of 24.2\% (442 of 1824), ranging across areas from $9.1 \%$ to $29.1 \%$. In areas not subject to our pilot open data policy, we nevertheless have a voluntary opt-in rate of $27.2 \%$ (334 of 1230), ranging from $9 \%$ to 50\% across subject areas.

For the European Commission, priorities include raising awareness regarding data management, interoperability of infrastructure and datasets, and re-usability of data. This is also linked to the ongoing copyright reform, especially with respect to text and data mining.

\section{The challenge of Open Science}

For the European Commission, 'Open Science' is the transformation, opening up and democratisation of science, research and innovation, with the objective of making science more efficient, transparent and interdisciplinary, of changing the interaction between science and society, and of enabling broader societal impact and innovation. We seek not just to define open science but also give it purpose.

The operationalization of open science requires the emergence of a new ecosystem of standards and services. Open Access and Open Research Data are key components, facilitating the emergence of new infrastructure for data and publications. That infrastructure is not only about objects (e.g. data or publication repository), but also about workflows resulting in data and publications, and the evaluation and use of research results, e.g. impact measurement, validation, commercial exploitation.

Particularly the later dimension, the evaluation and use of research results throws into focus the wider social and political embedding of open science. Overall, the European Commission has identified four areas of notable challenges for driving forward open science, cutting across workflows, objects, and post-publication usage scenarios (see Fig. 1).

Two further more transversal dimensions bring these elements together: (1) research evaluation and metrics (i.e. how research outputs and careers are measured) and (2) what impact research and science can have on growth and innovation, and therefore ultimately for society.

The European Commission is commencing a policy process on open science.

Open science strengthens the link between science and society, for example increasing the transparency of evidence-based policy-making. It also enables society to handle the 'data deluge' more effectively as service providers may step in to curate and evaluate data for interested users. 


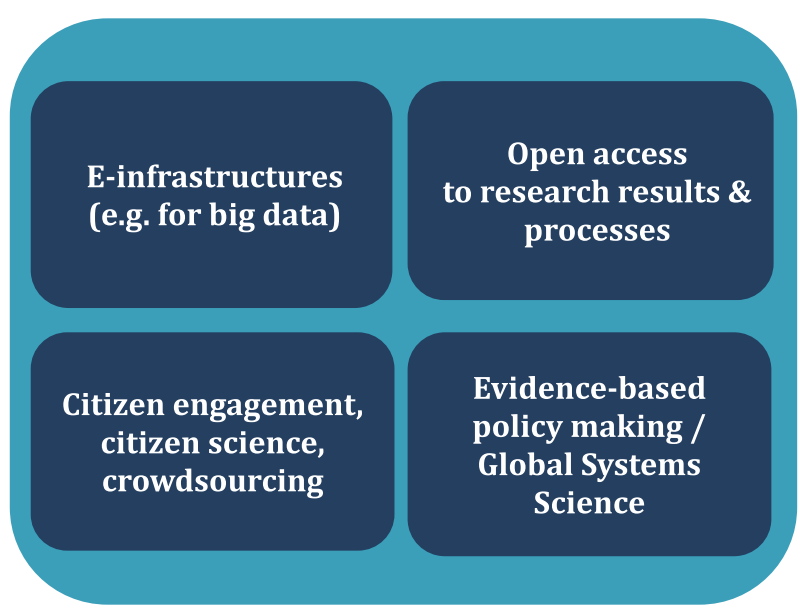

Fig. 1. Four challenges for driving open science. (Colors are visible in the online version of the article; http://dx.doi.org/10. 3233/ISU-150777.)

Open science facilitates new avenues of engagement and funding, for example by 'crowds' of peoples and charities seeking improved health outcomes. It also facilitates rapid worldwide re-use and deployment in education, be it for professional purposes or in schools.

We believe that, for Europe, Open Science will become a key driver of innovation. 